\title{
An Argument Against Reduction in Morality and Epistemology
}

\author{
Jeremy Randel Koons, American University of Beirut
}

Many naturalistically-minded philosophers want to accomplish a naturalistic reduction of normative (e.g. moral and epistemic) claims. Mindful of avoiding the naturalistic fallacy, such philosophers claim that they are not reducing moral and epistemic concepts or definitions. Rather, they are only reducing the extension of these normative terms, while admitting that the concepts possess a normative content that cannot be naturalistically reduced. But these philosophers run into a serious problem. I will argue that normative claims possess two dimensions of normativity. I will further argue that certain of the reductionist's commitments require that these two dimensions of normativity be given a naturalistic reduction, while the other of the reductionist's commitments make such a reduction impossible. Thus, the reductionist's commitments both require and forbid a reductionist account of morality and epistemology. Thus, as we will see, reductionism is torn between two incompatible requirements, and must fail.

\section{The Reductionist Strategy}

It is a commonplace that our most successful project of inquiry is that of science. There is an ongoing debate among philosophers as to how closely fields such as ethics and epistemology need to resemble science in order to secure legitimacy for themselves. Thus, Darwall, Gibbard, and Railton write that

$[\mathrm{W}]$ hat is our going view of the world? Perhaps most contemporary philosophers would agree that our going view treats empirical science as the paradigm of synthetic knowledge, and that an acceptable account of ethics must "place" it with respect to this paradigm, either by effecting some sort of methodological (and 
perhaps also substantive) assimilation ... or by establishing a convincing contrast. ${ }^{1}$

Those philosophers who seek to establish "a convincing contrast" include, e.g. "non-naturalists" who reject what they call a "scientistic" approach to philosophy and hold that morality and epistemology should not be required to resemble scientific projects.

On the other hand, many other philosophers impressed by the success of science and suspicious of properties that lack scientific or causal-explanatory credentials have argued that our philosophical inquiry ought more closely imitate the methods and canons of science. Of course, some of these scientifically-minded philosophers hold that morality and epistemology cannot meet this challenge. We might call such philosophers eliminativists. Eliminativists on the moral side (often called "nihilists") include, for example, Harman (who describes himself as a "moderate nihilist"). On the epistemic side, we have, for example, the Quine of "Epistemology Naturalized." There, Quine argues that we should quit doing epistemology and turn instead to psychology to explain human belief. Another sceptic about epistemological normativity is Robert Black. ${ }^{2}$

More interesting perhaps are those philosophers who pursue what Darwall, Gibbard and Railton term as a "substantive assimilation" of morality and epistemology to science. These philosophers reject the elimination of normative (e.g. moral and epistemological) vocabulary and instead embrace reduction, the thesis that normative properties are reducible to natural ones. Thus, a moral property such as morally right might be claimed to be equivalent to the natural property maximises utility, or some disposition to approve; an epistemic property such as epistemically justified might be claimed equivalent to the natural property formed by a reliable belief-causing mechanism, and so forth. These natural properties are respectable, it is thought - they can be investigated by the empirical sciences, they can be legitimately used in causal explanations, and so forth. ${ }^{3}$ Normative properties, it is

1. John Darwall et al., "Toward Fin de siècle Ethics: Some Trends." The Philosophical Review, v. 101 (1992, p. 126).

2. Robert Black, "Moral Scepticism and Inductive Scepticism." Proceedings of the Aristotelian Society, (1989-90) pp. 65-82.

3. One of the best known arguments that only causally efficacious properties are legitimate ones is Chapter 1 of Gilbert Harman's "Rule-Following, Objectivity, and Meaning." In B. Hale and C. Wright (eds.) Companion to the Philosophy of Language (Oxford: Blackwell Publishers, 1977) pp. 369-396. 
thought, can thereby inherit their respectability - indeed, their very legitimacy - from these natural properties. It is these philosophers who pursue reductionism, where the reduction is "in the form of. . . a synthetic identity statement" - i.e. a statement about the coextensiveness of moral (or epistemic) and natural terms. This view is echoed by James Rachels, who writes that

Ethical naturalism is the idea that ethics can be understood in the terms of natural science. One way of making this more specific is to say that moral properties (such as goodness or rightness) are identical with "natural" properties, that is, properties that figure into scientific descriptions or explanations of things ... Thus, C.D. Broad observed that "If naturalism be true, ethics is not an autonomous science; it is a department or an application of one or more of the natural or historical sciences" (Broad 1946, 103). ${ }^{5}$

Such a reduction of the moral and epistemic to the natural is supposed to ease some of the worries that naturalistically-minded philosophers have about normative discourse. Thus, Peter Railton writes:

If, for example, moral facts are identified with - or otherwise reducible - to natural facts, then there is no special mystery about what sort of things they are, or how we come to have knowledge of them, refer to them, and so on ... If moral facts are identical with - or otherwise reducible to - natural facts, then cognitivism may be possible without worrisome ontological expansion. ${ }^{6}$

Railton also notes that "the naturalist in ethics can be a naturalist in epistemology." 7 The reasons that drive one towards naturalism in ethics, of course, will tend to push philosophers towards a naturalisation of all types of normative discourse. Other philosophers demand naturalistic reduction of moral facts as a very condition of the legitimacy of such facts. Harman writes that "there is no way to test moral claims empirically, unless they are reducible to naturalistic claims." ${ }^{\prime}$ And, of course, Harman is famous for arguing that to

4. Darwall et al. (1992, p. 174).

5. J. Rachels, "Naturalism." In H. LaFollette (ed.), The Blackwell Guide to Ethical Theory (Malden, MA: Blackwell Publishers, 2000) p. 75.

6. P. Railton, "What the Non-Cognitivist Helps Us to See the Naturalist Must Help Us to Explain." In J. Haldane and C. Wright (eds.), Reality, Representation, and Projection (New York: Oxford University Press, 1993) p. 280.

7. Railton (1993, p. 281).

8. G. Harman, "Moral Explanations of Natural Facts - Can Moral Claims Be Tested Against Moral Reality?" The Southern Journal of Philosophy. (Suppl. 24, 1986) p. 58. 
be legitimate, moral claims must be capable of empirical testing. Sturgeon, discussing the idea that there are irreducibly moral truths, argues that "this retreat [would] certainly make it more difficult to fit moral knowledge into anything like a causal theory of knowledge, which seems plausible for many other cases, or to follow Hilary Putnam's suggestion that we "apply a generally causal account of reference ... to moral terms' (Putnam, "Language and Reality," in Mind, Language, and Reality: Philosophical Papers, vol. 2 [Cambridge, 1975], p. 290)."10

At this point, a possible problem arises for the naturalist: any attempt to reduce normative concepts without remainder to natural concepts runs afoul of the naturalistic fallacy, since moral and epistemic concepts are normative, and natural concepts are nonnormative. Thus, it is claimed, any attempt simply to identify normative concepts with non-normative concepts is illegitimate. Normative concepts are thought to have a normative conceptual surplus that defies outright naturalistic reduction. This point has been long recognised. Consider what Wilfrid Sellars wrote over 50 years ago in "A Semantical Solution of the Mind-Body Problem."11 Suppose we endorse the following equivalence:

$$
\mathrm{X} \text { is morally right }=\mathrm{X} \text { maximises happiness }
$$

Sellars argues that this equivalence cannot be the whole story: whatever " $\mathrm{X}$ is morally right" might refer to, it says that " $\mathrm{X}$ is morally right," and that cannot be said using purely descriptive vocabulary. As Sellars writes, "Whatever users of normative discourse may be conveying about themselves and their community when they use normative discourse, what they are saying cannot be said without using normative discourse." ${ }^{\prime 2}$ Sellars makes a similar point, specifically about epistemology, in "Empiricism and the Philosophy of Mind":

Now the idea that epistemic facts can be analyzed without remainder - even "in principle" - into non-epistemic facts, whether phenomenal or behavioral, public or private, with no matter how

9. See chapter 1 of Harman (1986).

10. N. L. Sturgeon, "Moral Explanations." In G. Sayre-McCord (ed.), Essays on Moral Realism (Ithaca, NY: Cornell University Press, 1988) pp. 235-236.

11. W. Sellars, "A Semantical Solution of the Mind-Body Problem." In J. F. Sicha (ed.), Pure Pragmatics and Possible Worlds: The Early Essays of Wilfrid Sellars (Atascadero, CA: Ridgeview Publishing Company, 1980).

12. Sellars (1980, p. 256). 
lavish a sprinkling of subjunctives and hypotheticals is, I believe, a radical mistake - a mistake of a piece with the so-called "naturalistic fallacy" in ethics. ${ }^{13}$

Contemporary reductionists respond to this worry by distinguishing between the coextensiveness of moral and non-moral terms and their synonymy. Thus, while a moral phrase, such as "morally right," might have the same extension or reference as the non-moral phrase "maximises utility," these two phrases do not mean the same thing. A phrase such as "morally good" might be extensionally equivalent to "maximises utility," but there is a normative surplus, which is not a feature of the extension of the phrase "morally good," but instead is a feature of the phrase's meaning. Thus, the well known distinction between meaning and reference is pressed into service for the reductionist agenda. This approach is reflected in the earlier quote from Rachels, who asserts the identity of moral and natural properties; and the quote from Darwall, Gibbard and Railton, who speak of synthetic (as opposed to analytic) identity statements. A similar approach can be seen in the work of various naturalised epistemologists. Hilary Kornblith, e.g. writes that, "The goal of a naturalistic theory of knowledge, as I see it, is not to provide an account of our concept of knowledge, but instead to provide an account of a certain natural phenomenon, namely, knowledge itself."14

Indeed, this move is made by a wide range of naturalisticallyminded philosophers. Let us see an example of how the distinction between coextensiveness and synonymy is used to defend ethical naturalism from accusations that it runs afoul of the naturalistic fallacy. Brink (1989) defends ethical naturalism. Although Brink defends a non-reductive version of naturalism, we can learn from his discussion of whether ethical naturalism is threatened by the is/ought thesis, the thesis that one cannot derive an "ought" statement from any conjunction of "is" statements. One prominent attempt to wield the is/ought thesis against ethical naturalism is the "open question" argument of G. E. Moore. Moore writes,

But whoever will attentively consider with himself what is actually before his mind when he asks the question 'Is pleasure (or

13. Sellars (1997, p. 19).

14. H. Kornblith, "In Defense of Naturalized Epistemology." In J. Greco and E. Sosa (eds.), The Blackwell Guide to Epistemology (Malden, MA: Blackwell Publishers, 1999) p. 161. 
whatever it may be) after all good?' can easily satisfy himself that he is not merely wondering whether pleasure is pleasant. And if he will try this experiment with each suggested definition in succession, he may become expert enough to recognize that in every case he has before his mind a unique object, with regard to the connection of which with any other object, a distinct question may be asked. Everyone does in fact understand the question 'Is this good?' When he thinks of it, his state of mind is different from what it would be were he asked 'Is this pleasant, desired, or approved?' It has a distinct meaning for him. ${ }^{15}$

Moore's argument relies on a particular version of the is/ought thesis, namely the semantic thesis, which "requires that there be no relations of synonymy or meaning implication between moral and non-moral terms." 16 Relying on this version of the is/ought thesis, Brink explains Moore's argument as follows:

If two terms are synonymous, then, by the traditional theory of meaning, any speaker competent with both must associate the same criteria or set of properties with both. Then, if two terms are synonymous and a speaker is competent with both, she cannot sensibly doubt whether their meaning is the same. But whereas it is never possible to doubt whether $\mathrm{F}$ is $\mathrm{F}$, it is always possible to doubt whether F is G. So, 'F' and ' $G$ ' cannot be synonymous . . . It is concluded that there can be no meaning implications between moral and nonmoral terms. ${ }^{17}$

This argument might be thought to rule out any necessary connection between moral and non-moral properties; it might also be thought to rule out the possibility that moral properties are constituted by or reducible to natural properties. However, Brink notes that the open question argument relies on what Brink calls the "semantic test of properties," namely, "the claims that synonymy is a test of property identity and that meaning implication is a test of constitution or necessitation." ${ }^{18}$ But there is good reason to reject the semantic test of properties. Let me quote Brink at length, as this will allow us to see the emergence of the sort of strategy I have been attributing to the naturalist:

15. G. E. Moore, Principia Ethica (Cambridge: Cambridge University Press, 1903) pp. 16-17. Quoted in D. O. Brink, Moral Realism and the Foundations of Ethics (New York: Cambridge University Press, 1989) p. 152.

16. Brink (1989, p. 152).

17. Brink (1989, pp. 152-153).

18. Brink (1989, p. 162). 
Philosophers of language, such as Saul Kripke.... and Hilary Putnam . . . have argued recently that we cannot maintain both the traditional theory of meaning according to which the meaning of a term is the set of properties that any speaker competent with the term associates with the term and the semantic test of properties according to which meaning determines intension. If they are right and we accept the traditional theory of meaning that underlies the semantic thesis ... we must reject the semantic test of properties that underlies [the open question argument]... [S]ynonymy is neither a necessary nor a sufficient condition for property identity, and meaning implication is neither a necessary nor a sufficient condition for either constitution or strong supervenience. But this means that the semantic thesis has no bearing on naturalism ... Even if the semantic thesis is true, nothing about the legitimacy of naturalism in ethics or elsewhere follows. The naturalist can concede that there are neither synonymies nor meaning implications between moral and nonmoral, for instance, natural, terms and still maintain that moral facts and properties are identical with, or constituted by, natural and social scientific facts and properties. The naturalist's identity or constitution claims can be construed as expressing synthetic moral necessities... [Thus, we can] accept the is/ought thesis and the traditional theory of meaning underlying the semantic thesis ... and reject the semantic test of properties. This allows us to defend ethical naturalism .. even if there is an is/ought gap. ${ }^{19}$

Thus, Brink recognises that the is/ought gap is a barrier to meaning identity between moral and natural terms, but rescues naturalism by distinguishing between identity of meaning and identity of reference or extension. Moral properties can be identical to, or constituted by, natural properties, even if moral and natural terms cannot have the same meaning.

Other naturalists follow a similar line. One moral philosopher has gone so far as to write that "Kripke-Putnam semantics renders Moore's open-question argument obsolete." ${ }^{20}$ Putnam himself writes that Moore's open question argument fails to recognise "that there could be such a thing as synthetic identity of properties . . . Moore conflated properties and concepts." ${ }^{21}$ Richard Boyd writes:

19. Brink (1989, pp. 166-167).

20. W. Fenske, "Non-Cognitivism: A New Defense." The Journal of Value Inquiry, v. 31, 1997, p. 301.

21. H. Putnam, Reason, Truth, and History (Cambridge: Cambridge University Press, 1981) pp. 206-207. 
[C]onsider the objection that a moral realist must hold that goodness is a natural property, and thus commit the 'naturalistic fallacy' of maintaining that moral terms possess analytic definitions in, say, physical terms. The moral realist may choose to agree that goodness is probably a physical property but deny that it has any analytic definition. ${ }^{22}$

In a similar vein, James Rachels, discussing Moore's open question argument, writes:

Are these arguments effective? It depends on what, exactly, we take naturalism to be. Naturalism can be construed as a thesis about the meaning of words - that, for example, the word "good" means "satisfies our interests." If this is how we understand the theory, Moore's arguments are plausible... But ethical naturalism can also be understood, more interestingly, as an idea about what goodness is that it is, for example, the same thing as the property of satisfying our interests. Moore's arguments do not touch this idea at all. ${ }^{23}$

Ralph Wedgwood makes an identical move in responding to a suspiciously open-question sounding objection from Mark Johnston:

Many arguments have been offered in support of the claim that moral properties are irreducible ... A great number of these arguments appeal, in effect, to a difference between the cognitive role played by moral concepts and the role played by the naturalistic concepts used in the purported reduction. Thus, for example, Mark Johnston claims that, if you learn that something satisfies some naturalistic description (for example, if you learn that it is something that you would desire to desire if you were fully informed), you could quite rationally dismiss this information as irrelevant, with the feeling 'So what?' - whereas it could not be rational to respond in this way to the information that the thing in question is good or valuable (Johnston 1989, 157-158). But even if this claim is true, it does not support the claim that values are irreducible. The fact that there is an important difference between two concepts does not show that there is a corresponding difference between the properties that the two concepts stand for. Otherwise, we could show that the property of being made of water is distinct from the property of being made of $\mathrm{H}_{2} \mathrm{O}$, since there are clearly sharp differences between the cognitive role of the concept $\mathrm{H}_{2} \mathrm{O}$ and that of the concept water. ${ }^{24}$

22. R. N. Boyd, "How to Be a Moral Realist." In G. Sayre-McCord (ed.), Essays on Moral Realism (Ithaca, NY: Cornell University Press, 1988) p. 199.

23. Rachels (2000, p. 75).

24. R. Wedgwood, "The Price of Non-Reductive Moral Realism." Ethical Theory and Moral Practice v. 2, 1999, p. 206. 
Again and again, we see the strategy and motivation I have attributed to the naturalist. The naturalist begins with the worry that normative and naturalistic concepts play a different "cognitive role." As I have argued, moral and epistemic concepts have a normative content which a naturalistic concept lacks. But, the naturalist argues, this fact only rules out identifying moral and natural concepts, while allowing identification of moral and natural properties. Moore's open question argument and similar deployments of the is/ought thesis rule out a definitional equivalence between moral and natural concepts; but naturalists seek to avoid these arguments by claiming instead the coextensiveness of such concepts, not their identity. Goodness turns out to be maximisation of utility, a particular homeostatic property cluster ${ }^{25}$, or some similar naturalistically-specifiable property or entity. These naturalistic philosophers often take advantage of direct theories of reference of the sort pioneered by Kripke and Putnam to assimilate moral kinds to natural kinds, and thus bring moral entities under the causal theory of reference. ${ }^{26}$

Thus, in reducing normative to natural properties, reductionists are reducing only the extension of normative terms. On top of the extension of terms such as "right," "justified," and so on, there is a normative surplus which is not reduced. This surplus is supposed to be a feature of the normative term's meaning, not its extension. And so in this way, epistemologists and moral philosophers hand off this normative conceptual surplus to philosophers of language, to be dealt with by a theory of meaning.

Unfortunately, it does not seem that a theory of meaning can cope with this normative conceptual surplus while remaining true to the motivation that drove philosophers in the first place to restrict their reductionism to a reduction of extension, not of meaning. In other words, the same arguments that lead philosophers to reject the notion that moral or epistemic terms could be synonymous with

\footnotetext{
25. Boyd (1988) develops the notion of a homeostatic property cluster.

26. Of course, this move in ethics has been extensively criticised by Horgan and Timmons $(1991,1992,2000)$ in their series of "Moral Twin Earth" articles. However, it is not my intention to pursue their line of attack. I am willing to grant, for the sake of argument, that the direct reference theory can be made to work for moral and epistemic kinds. But I want to ask what happens to the normative surplus, which is pushed off onto the theory of meaning - can the naturalist deal with this normative surplus while remaining true to her reductive motivations? I will argue that she cannot.
} 
natural terms seem to forbid a reductionist account of meaning, whereas the motivation that drove philosophers to seek reductive theories of morality and epistemology seems to require a reductionist account of meaning. Thus, as we will see, reductionism is torn between two incompatible requirements.

\section{Normativity and the Meaning of Normative Expressions}

It is accepted by most philosophers that meaning is normative. That is, rules governing meaning are norms of correctness, and one who deviates from such a norm has done something wrong, something incorrect. Thus, the normativity of meaning is often construed as a point about the possibility of error. One who has misused a word has done something wrong, whereas if someone merely deviates from a disposition, this does not automatically count as an error. These points are familiar to readers of Wittgenstein ${ }^{27}$ and $\mathrm{Kripke}^{28}$, and are widely accepted in contemporary philosophy of language. Bob Hale has gone so far as to describe the normativity of meaning as an "undisputed feature of the concept of meaning," ${ }^{29}$ although in this he perhaps goes too far.

But a claim about the meaning of a normative (e.g. moral or epistemological) phrase is doubly normative. Consider such a meaning claim:

M: "X is morally right for S" means (in part) "S ought to do X"

$\mathrm{M}$ is normative in the sense that all meaning claims are normative. "A means B" has a normative element to it as described above. But claims such as $M$ possess a second normative element: the moral concept's normative surplus, the surplus that could not be reduced to a naturalistic fact, is expressed by the meaning claim. So $\mathrm{M}$ is normative not just in the virtue of containing the term "means," but also in the virtue of expressing (via the phrase "S ought to do X") the normative component of the moral claim " $\mathrm{X}$ is morally right

27. L. Wittgenstein, Philosophical Investigations, G. E. M Anscombe, trans. (New York: Macmillan Publishing Company, Inc., 1958).

28. S. Kripke, Wittgenstein on Rules and Private Language (Oxford: Basil Blackwell Publishers, 1982).

29. B. Hale, "Rule-Following, Objectivity, and Meaning." In B. Hale and C. Wright (eds.) Companion to the Philosophy of Language (Oxford: Blackwell Publishers, 1997) p. 392. 
for S." We might call these two normative components as M's semantic normativity and its moral normative content. (Sentences about the meaning of normative epistemic terms would possess semantic normativity and epistemic normative content, and so forth).

This double normativity of sentences like $M$ presents a double problem for reduction-minded philosophers. First, let us ask whether the moral normative content of $\mathrm{M}$ can be given a naturalistic reduction. $M$ claims that "X is morally right for $S$ " means (in part) " $S$ ought to do X." But what is it for a sentence to mean that S ought to do X? It seems as though we cannot give a reductive answer to this question. The very motivation which drove the naturalist to deny that " $\mathrm{X}$ is morally right" could mean the same thing as " $\mathrm{X}$ maximises utility" - the idea that such reduction committed the naturalistic fallacy, and failed to respect the normative component of " $\mathrm{X}$ is morally right" - will forbid a reductive account of what it is for a sentence to mean that $\mathrm{S}$ ought to do X. That is, this motivation will forbid a naturalistic reduction of the moral normative content of $\mathrm{M}$. E.g. suppose we endorse a simple dispositionalist theory of meaning and claim that the sentence $M$ means that, in the long-run, the majority of people would be disposed to condemn $\mathrm{S}$ for failing to do X. We can hear Sellars spinning in his grave, while his ghost intones:

"S ought to do X" might convey the same thing as "in the longrun, the majority of people would be disposed to condemn S for failing to do X," but whatever the former phrase might convey, it says something very different from the latter. It says that $\mathrm{S}$ ought to do $\mathrm{X}$, and this is something that cannot be reduced to a mere description of circumstances (even one that contains a counterfactual element). ${ }^{30}$

The reductive naturalist must agree with this sort of reasoning. After all, it was reasoning of this precise sort that led the reductive naturalist to concede that naturalism can only equate the extension of normative and descriptive terms, but never their meaning. That is, if the normative content of a moral phrase (such as " $\mathrm{X}$ is morally right for S") cannot be reduced to a set of natural facts (a consideration which motivated the naturalist in the first place to distinguish between coextensiveness and synonymy of normative and

30. I am putting words in Sellars's mouth here, but given the earlier quotes, I cited from Sellars, this passage expresses a position Sellars clearly would endorse. 
natural terms), then it cannot be reduced to a set of natural facts by the moral philosopher or by the philosopher of language. The shift of context from moral philosophy to philosophy of language should not alter that fact.

Notice that I am not (yet) denying that a dispositionalist account of meaning will work for the meaning of non-normative sentences. ${ }^{31}$ Thus, one is not obviously committing the naturalistic fallacy in claiming that

"Water" means "the clear stuff that runs in streams, is potable, etc." is equivalent to

In the long run, people will be disposed to use the term 'water' to refer to the clear stuff that runs in streams, is potable, etc.

What I am denying is that such a reduction will work with an explicitly normative sentence like $M$; such reduction does seem to commit the naturalistic fallacy. And so, as I argued above, the same motivation that drove the naturalist to embrace the coextensiveness rather than the synonymy of normative and natural terms must also drive the naturalist to reject reductive accounts of the meaning of normative sentences like $\mathrm{M}$.

Let us consider the matter this way. Reduction of the extension of moral and epistemic terms left, as a residue, a normative conceptual surplus that could not be reduced, due to the sui generis nature of the normative with respect to the natural. This normative conceptual surplus is then pushed off on to the theory of meaning. But the same sui genericity that prevented a naturalistic reduction of this normative content in our moral and epistemic theories stands in the way of a naturalistic reduction of this same content when it is handled by our theory of meaning.

Thus, it seems that the naturalist must countenance a nonreductive theory of meaning. But notice that this undercuts the entire motivation for being a reductionist in the first place. The whole point of being a reductionist is that only naturalisticallydescribable properties are legitimate, and so if normative vocabulary

31. Wittgenstein is, of course, famous for arguing that such dispositionalist accounts of meaning failure due to the normativity of meaning. We will see, in a moment, how the normativity of meaning, as recognised by Wittgenstein and others, presents an additional obstacle to the reductionist philosopher. 
is to be respectable, it must be coextensive with (i.e. reducible to) naturalistic vocabulary; only naturalistic facts are causally efficacious and therefore countenanced by a scientific world view. But if the naturalist is willing to admit that semantic vocabulary is legitimate but irreducible, then the naturalist's pro-reduction arguments in morality and epistemology fail any more to convince.

The arguments in favor of reductionism in morality and epistemology, which we cited at the beginning of the paper, can just as easily be rephrased to encompass semantics. That is to say, those who argue for the importance (or even the necessity) of reducing morality and epistemology, can easily have their arguments turned to require the reduction of semantics as well. We can rephrase the Harman quote from the beginning of the paper as follows: "There is no way to test semantic claims empirically, unless they are reducible to naturalistic claims." And the quote from Sturgeon at the beginning of the paper can be changed to read, "If we concede that there are irreducibly semantic truths, this retreat would certainly make it more difficult to fit semantic knowledge into anything like a causal theory of knowledge, which seems plausible for many other cases, or to follow Hilary Putnam's suggestion that we 'apply a generally causal account of reference...to [semantic] terms' (Putnam, "Language and Reality," in Mind, Language, and Reality: Philosophical Papers, vol. 2 [Cambridge, 1975], p. 290)." What is sauce for the goose is sauce for the gander: the same arguments the reductionists employ in morality and epistemology can be turned against non-reductive theories of the meaning of normative terms. It seems, then, that reductionism defeats itself. The arguments employed by the reductionists require a reductive account of the meaning of sentences like $M$, but the reductionist's commitment to avoiding the naturalistic fallacy forbids such a reduction.

Matters get worse though. For we noted that claims about the meaning of normative expressions possess two kinds of normativity: (i) moral (or epistemic) normative content, and (ii) semantic normativity. We have already seen how moral and epistemic normative contents represent a barrier to a reductive account of the meaning of normative claims. However, many philosophers have argued that the semantic normativity of meaning claims also stands in the way of a reductive theory of meaning. As we noted above, meaning claims are normative - they possess semantic normativity. Let us see how one philosopher argues that semantic normativity stands in the way 
of a reduction of meaning. Eric H. Gampel argues that the meaning is normative in the sense that it is essential to meaning that it will be able to justify the use. Gampel states this thesis in the following form:

Essential Justificatory Role of Meaning ("EJRM"): being able to justify a person's use of an expression is essential to meaning. ${ }^{32}$

This creates a problem for reductionist theories of meaning. "The general problem," Gampel argues,

is that it is hard to see how it could be essential to natural items, specifiable from within the natural sciences, to have a capacity to justify... [T]he paradigm here is the difference between something like a straightedge or the meter bar, on the one hand, and such things as rules and values on the other. While it seems essential to a rule, or to a fact about a rule, that it have a capacity to justify, it does not seem essential to natural objects or facts to be able to do so ... Physical facts about the meter bar certainly could justify various measurement claims, but it was not essential to them to be able to do so... So EJRM, if right, would provide the basis for a prima facie case against identificatory reductions of meaning facts. ${ }^{33}$

So it is essential to a meaning fact that it be able to justify, but no natural fact essentially possesses this justificatory efficacy. Thus, semantic normativity stands in the way of any reductive account of meaning.

Other philosophers have also argued that the normativity of meaning stands in the way of a reductive account of semantic terms. As I noted earlier, the thesis that meaning is normative is often cast in terms of the possibility of error. One who has misused a word has done something wrong, whereas if someone merely deviates from a disposition, this does not automatically count as an error. But it is precisely in connection with the possibility of error that naturalised semantic accounts tend to fail; their failure on this count is systematic. Barry Loewer, after surveying critically several of the dominant naturalised semantic projects in the literature, writes that, "None of

32. E. H. Gampel, "The Normativity of Meaning." Philosophical Studies, v. 86, 1997, p. 229. Emphasis is altered from the original.

33. Gampel (1997, 231-232). I will not pursue Gampel's argument further here, as my thesis stands independently of his thesis, and as the readers who are interested in the details of Gampel's argument will no doubt find the original article more enlightening that any synopsis I might give. 
the naturalization proposals currently on offer are successful. We have seen a pattern to their failure. Theories that are clearly naturalistic ... fail to account for essential features of semantic properties, especially the possibility of error and the fine-grainedness of content." ${ }^{34}$ Thus, the possibility of error lies at the heart of the doctrine of semantic normativity, and also represents a major stumbling block to naturalised semantic theories. This suggests strongly that it is the absence of a normative component that leads these naturalised semantic theories to fail. Indeed, Peter Godfrey-Smith reluctantly concludes that the problem of error may be insurmountable for naturalised semantics:

It is well-known that information theories of representation have trouble accounting for error... Informational semantics apparently cannot explain how a representation can acquire a determinate content and yet be false... Before pressing on, I pause to stress the gravity of these issues. Informational semantics is almost the only theory in an important philosophical market. The market is the naturalistic explanation of intentionality, and ultimately, of truth and reference... We [will] survey existing treatments of error in informational semantics, focusing especially on the work of Fodor and Dretske. None of these treatments solves the problem, we will find, or even comes close. My general, and very reluctant, conclusion is that the error problem is indeed something informational semantics might never overcome. ${ }^{35}$

Other philosophers draw similar conclusions. Paul Boghossian writes that "Reductionist versions of [semantic] realism appear to be false... Meaning properties appear to be neither eliminable, nor reducible." 36

Semantic normativity is a vexed issue, and I will not pursue these arguments further here. Even if one denies that semantic normativity is a barrier to a reductive account of meaning (indeed, even if one denies that there is semantic normativity), the thesis of this paper remains intact, since moral (and epistemic) normative contents remain a barrier to a fully reductive theory of the meaning of normative expressions.

34. B. Loewer, “A Guide to Naturalizing Semantics.” In B. Hale and C. Wright (eds.), A Companion to the Philosophy of Language (Oxford: Blackwell Publishers, 1997) p. 121. Emphasis is added.

35. P. Godfrey-Smith, "Misinformation." Canadian Journal of Philosophy, v. 19, 1989, pp. 533-534.

36. P. A. Boghossian, "The Rule-Following Considerations." Mind, v. 98, 1989, pp. 547-548. 
Thus, both the semantic normativity and the moral normative content (or epistemic normative content, etc.) of sentences like $\mathrm{M}$ stand in the way of an entirely reductive theory of meaning. But, as I noted earlier, the failure of naturalistic theories of meaning undercuts the motivation for being a reductionist in other areas of philosophy, such as epistemology and moral theory. Thus, the reductionist project in morality turns out to be self-defeating.

\section{Non-Semantic Normative Content}

There is another option the reductionist might wish to explore. The naturalist might argue that the normative surplus, which was not reduced, is not a feature of the moral term's meaning, but is accounted for in some other way. For example, suppose we claim that the term "good" refers to the maximisation of utility. That is, goodness is identified with the maximisation of utility via a synthetic identity statement. However, one might go on to claim that the normativity of goodness is not a feature of the meaning of the term "good." Rather, the normativity of goodness consists in (let us say) the ability of goodness to motivate the perceivers of the good. ${ }^{37}$ I.e. goodness (i.e. utility maximisation) has a certain "to be doneness," which causes normal moral agents to act in order to achieve the good.

This solution to the problem of normativity would obviate the initial problem, since there would no longer be any problem with saying that moral and epistemic terms are synonymous with natural terms. After all, if moral and epistemic terms do not have any normative meaning, then there is no problem with saying that such terms are synonymous with natural terms or phrases such as "maximises utility" or "produced by a reliable belief-forming mechanism."

This move would certainly take metaethicists (and metaepistemologists) by surprise, since most of these philosophers seem to think that moral and epistemic concepts have normative content. After all, if these naturalists did not think this, then they would not be devoting so much energy to avoiding Moore's open question argument

37. No reductionist would, in fact, endorse this account of the normativity of moral goodness. I am merely using this contrived example to illustrate a point. 
and the naturalistic fallacy. Thus, to deny that moral and epistemic concepts have normative content is to go against the established consensus of the philosophers quoted in the first section of the paper, those naturalist philosophers who take for granted that moral and epistemic concepts do have normative content. This, in itself, is not a telling objection against this proposed move; but it does suggest that the burden of proof is on the person who wants to deny normative content to moral and epistemic concepts.

In any case, there are independent reasons for thinking that this proposed move won't work. First, it seems absurd to deny that terms of moral and epistemic appraisal have normative meaning. But that is precisely what this solution is committed to denying: this solution says that the normativity of moral and epistemic terms (like "good," "right," "rational," etc.) is not a feature of the term's meaning. It must say this, since (as we saw above) a theory of meaning cannot reduce the normative content of moral and epistemic terms. Thus, if we are to be thoroughgoing reductionists, we must claim when I say, "Torturing cats is immoral" or "Belief in astrology is irrational" I am not making any sort of normative or evaluative claim. Again, though, this claim is prima facie absurd. When I say, e.g. "Murder is wrong," clearly this sentence means something normative: it means that murder is wrong, and this is a normative claim.

Second, by identifying normativity with some natural fact (e.g. the ability to motivate), this solution seems to run smack into Mackie's queerness objection. This point is particularly clear in the example I give earlier, where normativity is equated with the ability to motivate. If a natural fact is intrinsically-motivating, or reasongiving, or in some other way normative, then we are countenancing the existence of "queer" properties or facts. As Mackie writes, "The assertion that there are objective values or intrinsically prescriptive entities or features of some kind... is, I hold... false." 38

The final objection to this solution is that it does not respond to the original problem posited by this paper; it merely moves the bump in the rug without smoothing it down. The original problem - that the normative content of moral and epistemic utterances cannot be

38. J. L. Mackie, Ethics: Inventing Right and Wrong (London: Penguin Books, 1977) p. 40 . 
definitionally reduced - stems from the sui generis nature of the normative with respect to the purely physical. And so the same sort of reason which prevents the normative moral and epistemic surplus from being reduced in a theory of meaning prevents this same surplus from being reduced outside the theory of meaning. Consider again the suggestion that the normativity of morality is not a feature of the meaning of moral terms, but rather consists in the ability of goodness to motivate normal perceivers. This fails as an attempt to reduce the normative content of morality. To say that humans are necessarily motivated to do $\mathrm{X}$ is not the same as saying that $\mathrm{X}$ is good, or that humans ought to do X. Christine Korsgaard states the point elegantly in her Sources of Normativity, where she rejects theories that try to explain the source of normativity in terms of what we are motivated to do. Although she is, in this passage, writing about theories that explain moral behaviour in terms of evolutionarily-selected behavioural traits, the point she is making applies to our argument here:

One possibility ... in connection with that theory [is] that our moral instincts would be so strong that they could move us, or at least make us miserable, even if we decided that their claims on us were illegitimate. The theory might then explain moral conduct, including the conduct of people who know the theory. But it would not be normative, because the people themselves would not think that their conduct was justified. If they could cure themselves of their instincts, they would. ${ }^{39}$

The problem highlighted by Korsgaard is this: such a theory might be explanatory, but it is not justificatory. That is to say, it might explain why we behave as we do, but such descriptive regularities of behaviour cannot by themselves suffice to justify this behaviour. Thus, the normativity of morality cannot be reduced to the ability of moral facts, entities, or properties to motivate us. Further, the problem is general. It is not as though a different or better reduction might somehow reduce this normative content while preserving its normativity. Normative facts are normative facts, and an attempt to reduce them without remainder to natural facts (as the attempt to reduce moral normativity to the ability to motivate) strips these normative facts of their normativity.

39. C. M. Korsgaard, The Sources of Normativity (Cambridge: Cambridge University Press, 1996), pp. 87-88. 


\section{Practical Reason and Normativity}

Of course, no philosopher who identifies morality with some natural property (via synthetic identity statements) will say that the normativity of morality consists in the ability of moral facts to motivate. Such philosophers are too sensitive to the queerness objection to make such a move. I merely use that account of moral normativity as a readily accessible example of an attempt to reduce our troublesome normative surplus to a natural fact. The example was not chosen because it is something any reductionist actually says. Rather, it was chosen because it is easily understood and evaluated, and because it brings out clearly the problem that the reductionist is facing: the impossibility of reducing this normative surplus to a physical fact.

Indeed, many influential naturalists deny that moral facts are, in and of themselves, reason-giving. Most reductionists are externalists about moral reasons. Since there are many varieties of externalism about reasons, let me be clear about what I mean: such reductionists deny that being under a moral obligation to $\Phi$ entails that you have any reason to do $\Phi$. They might say that most people would have such a reason (given most people's interests and desires), but that moral obligations are not intrinsically reason-giving. For example, David Brink famously argues that correctly judging that you ought to $\Phi$ need give you no reason whatsoever to $\Phi .{ }^{40}$ Moral facts are not intrinsically reason-giving. If there is moral normativity, it stems not from moral facts or entities. Rather, it stems from our theory of reasons or rationality.

This, then, is the reductionist's final gambit. She might claim that our troublesome normative surplus is not a feature of the meaning of normative terms; nor is this normative surplus to be accounted for via some other (non-semantic) naturalistic facts, such as motivational force. Rather, this normative surplus is to be pushed off onto a theory of practical reason. The mere fact that an action would maximise utility does not in itself give agents a reason to perform this action; but a comprehensive theory of rationality might demonstrate

40. Brink (1989). As I will emphasise later, the fact that I am citing Brink here does not mean that Brink accepts the details of the move I am now discussing. Brink merely denies that moral facts are in themselves reason-giving; he does not deny that moral terms have normative meaning. 
that certain agents (hopefully, most humans) do indeed have a reason to perform utility-maximising actions. Thus, the action is not intrinsically reason-giving: i.e. the mere fact that such an action would maximise utility cannot bind all rational creatures and give them all a reason to perform this action, regardless of their subjective motivational set. But human agents, with characteristic human concerns, do indeed have a reason to perform such actions. In this way, the normative surplus is handed off to a general theory of practical reason. On this view, there is no specifically moral (or epistemic) normativity. There is the normativity constituted in practical reason, but morality and epistemology as such possess no normative or evaluative content of any kind.

Let us begin by noting that this theory is in certain respects implausible. This position already denies that moral and epistemic concepts have any normative content, a denial that (as we saw earlier) seems false. But this proposed solution has other problems. We may well concede that a person might not always have a reason to fulfill her moral and epistemic obligations. But on the view that we are discussing, the person who does not fulfill her moral or epistemic obligations does not thereby open herself to any sort of normative criticism, since morality and epistemology as such are not normative. Remember, on this view, all normativity is passed on to the theory of practical reason, and so if the person has no reason to follow her moral or epistemic obligations, then nothing is normatively amiss with her failure to do so. But this is implausible. Brink notes that even if we embrace externalism about moral reasons, "We could still charge people who violate their moral obligations with immorality, even if we could not always charge them with irrationality." ${ }^{, 41}$ But if there is no moral normativity as such, then to charge a person with immorality is not to evaluate the person at all, or to make any normative judgment of any kind. Similar comments apply to people who violate epistemic norms or standards.

To be fair, Brink is not committed to this implausible position (nor is any other philosopher I know of). But this is the position the reductionist has been driven to, so we must see if the reductionist can rescue her theory by pushing all normativity off onto the theory of practical reason. So far it does not look promising. But the

41. Brink (1989, p. 75). 
reductionist faces an additional difficulty. Even if we concede to the reductionist that morality and epistemology are not normative per se, the reductionist must still deal with the normative surplus she has pushed off onto the theory of practical reason. That is, this normative surplus must be reduced by the theory of practical reason, if the reductionist's physicalist dreams are to be realised.

While it is beyond the scope of this paper to fully analyse whether practical reason can be reduced to a set of natural facts, we can at least outline some reasons for regarding this project with a lack of optimism. First, we have seen that in the domains of morality, epistemology, semantics, and beyond, we cannot simply identify a normative fact with a set of physical facts. It is not clear why we should regard the realm of practical reasoning as different. Why won't the same problems crop up if we attempt to reduce normativity to a set of physical facts via a theory of practical reasoning? Indeed, it seems that these problems will recur. Suppose I have a decisive reason to maximise utility. Can this be reduced to (say) wanting to want to maximise utility? If I want to want to maximise utility, it still makes sense to ask whether this entails that I ought to maximise utility. (I suppose the reductionist could say that "I ought to do X" and "I want to want to do X" are coextensive, but not synonymous, but it should be clear by now that this move only passes the buck without really solving any of the reductionist's problems.)

There are further reasons for supposing that practical reason cannot be naturalised. Jean Hampton has recently argued forcefully for the conclusion that reason cannot be naturalised in this way. ${ }^{42}$ According to Hampton, both instrumental and non-instrumental reasons rely on the notion of objective authority - the notion that a person is bound by reason regardless of his or her desires or interests. Clearly, the notion of a categorical imperative embodies the idea of objective authority. Categorical imperatives are supposed to bind agents regardless of their desires, interests and preferences. Hypothetical imperatives, however, are (it is said) only binding on those who possess the end or desire embodied in the imperative. Nevertheless, Hampton argues, hypothetical imperatives still rely on the notion of objective authority. If you have a desire (or some end which you concede is valuable), then you have a reason to take the

42. J. E. Hampton, The Authority of Reason (Cambridge: Cambridge University Press, 1998). 
means to achieving that end, regardless of whether or not you believe or acknowledge that you have such a reason. Thus, the objective authority of reason seems to be a brute fact, independent of human psychology - a queer sort of fact indeed! As Hampton writes, "However contingent the hypothetical 'ought' is on a desire, it is still not the same as a desire; to say, therefore, that its objective normative authority is what moves us to act rationally is to analyze the "prescriptive force' of hypothetical imperatives such that it is identical to the prescriptive force of categorical imperatives." ${ }^{43}$ Thus, even hypothetical imperatives embody the notion of objective authority. And this notion - the notion of objective authority - is intrinsically offensive to the naturalist. Hampton writes:

Is the idea of objective authority acceptable from a naturalist standpoint? I . . argue that for two reasons it violates naturalist scruples: First, the idea of an authority that is objective is ineffable - that is, impossible to pin down in a way that seems to make sense. From a naturalist point of view, this ineffability militates against its being a real phenomenon in the world, and is instead a good indication that the authority of reasons is a psycho-social phenomenon. Second, central to moral objectivism is the idea that this authority is a kind of "compelling rightness" that exists independent of human psychology and culture, and that is that "for the sake of which" we act when we act morally. But I . . argue that explanations presupposing objective moral authority are instances of final cause explanations - a species of explanation that all scientific theories reject. Hence, basic to the scientific point of view is a repudiation of the idea that there is any compelling rightness in the world, or any entities that move or take action "for the sake of" something else. ${ }^{44}$

So we are now in a position to see where the reductionist is driven: if the reductionist can demonstrate convincingly that moral and epistemic concepts have no normative content, and if the reductionist can show that there is no moral or epistemic normativity, and if the reductionist can show that the normativity of practical rationality can be naturalistically reduced, then the reductionist can say that she has given a successful naturalistic reduction of morality and epistemology. The first hurdle seems difficult to surmount, as does the second, as does the third. In short, the prospects for fully

43. Hampton (1998, p. 163).

44. Hampton (1998, pp. 99-100). 
reductive theories of morality and epistemology do not look very good.

It may be that the argument of this paper can be extended to other forms of naturalism, such as supervenience naturalism. It may be difficult for such theories to give a fully naturalistic account of the normative content of moral and epistemic terms. Morality and epistemology may well supervene on the natural, but whether the normativity - the "to-be-doneness" - of (e.g.) moral rightness can be exhaustively explained by this supervenience base is another question altogether. Non-reductive naturalists such as Boyd and Brink recognise this problematic is-ought gap and typically react to it (as the reductionists did) by distinguishing between the meaning and the reference of normative terms. ${ }^{45}$ But this response threatens to recreate the original problem posed in this paper. So, as was the case with reductive naturalism, supervenience naturalism may leave the normative content of normative terms unexplained, or at least not explained in the terms congenial to naturalism. Thus, the normative content of moral and epistemic terms may present an obstacle to many versions of philosophical naturalism. Whether the argument of this paper can be extended to other forms of naturalism is a question which must, however, wait for another occasion.

\section{References}

Black, R. (1989-90). "Moral Scepticism and Inductive Scepticism," Proceedings of the Aristotelian Society, Vol. 90, pp. 65-82.

Boghossian, P. A. (1989). “The Rule-Following Considerations.” Mind Vol. 98 (392, October): 507-549.

Boyd, R. N. (1988). "How to Be a Moral Realist." In G. Sayre-McCord (ed.), Essays on Moral Realism. Ithaca, NY: Cornell University Press, pp. 181-228.

Brink, D. O. (1989). Moral Realism and the Foundations of Ethics. New York: Cambridge University Press.

Broad, C. D. (1946). "Some of the Main Problems of Ethics." Philosophy 31: 99-117.

45. See Boyd (1988) and Brink (1989), especially Chapter 6. 
Darwall, S., A. Gibbard and P. Railton (1992). "Toward Fin de siècle Ethics: Some Trends." The Philosophical Review 101 (1, January): 115-189.

Fenske, W. (1997). “Non-Cognitivism: A New Defense." The Journal of Value Inquiry 31: 301-309.

Gampel, E. H. (1997). "The Normativity of Meaning." Philosophical Studies 86: 221-242.

Godfrey-Smith, P. (1989). "Misinformation." Canadian Journal of Philosophy 19(4): 533-550.

Hale, B. (1997). "Rule-Following, Objectivity, and Meaning." In B. Hale and C. Wright (eds.) Companion to the Philosophy of Language. Oxford: Blackwell Publishers, pp. 369-396.

Hampton, J. E. (1998). The Authority of Reason. Cambridge: Cambridge University Press.

Harman, G. (1977). The Nature of Morality: An Introduction to Ethics. In G. Sayre-McCord (ed.) Essays on Moral Realism, (New York: Oxford University Press), pp. 119-124, (Ithaca, NY: Cornell University Press, 1977; Chap. 1 repr. as Chap. 6, 1998)

-. (1986). "Moral Explanations of Natural Facts - Can Moral Claims Be Tested Against Moral Reality?" The Southern Journal of Philosophy. Suppl. 24: 57-68.

Horgan, T. and M. Timmons. (1991). "New Wave Moral Realism Meets Moral Twin Earth," Journal of Philosophical." Research 16: 447-465.

—. (1992). "Troubles for New Wave Moral Semantics: The Open Question Argument Revived," Philosophical Papers 21 (3, November): $153-175$.

—. (2000). "Copping Out on Moral Twin Earth." Synthese 124 (July):139-152.

Johnston, M. (1989). "Dispositional Theories of Value," Proceedings of the Aristotelian Society 63: S139-S174.

Kornblith, H. (1999). "In Defense of Naturalized Epistemology." In J. Greco and E. Sosa (eds.), The Blackwell Guide to Epistemology. Malden, MA: Blackwell Publishers, pp. 158-169.

Korsgaard, C. M. (1996). The Sources of Normativity. Cambridge: Cambridge University Press.

Kripke, S. (1982). Wittgenstein on Rules and Private Language. Oxford: Basil Blackwell Publishers.

Loewer, B. (1997). “A Guide to Naturalizing Semantics.” In B. Hale and C. Wright (eds.), A Companion to the Philosophy of Language. Oxford: Blackwell Publishers, pp. 108-126. 
Mackie, J. L. (1977). Ethics: Inventing Right and Wrong. London: Penguin Books.

Moore, G. E. (1903). Principia Ethica. Cambridge: Cambridge University Press.

Putnam, H. (1975). Mind, Language, and Reality: Philosophical Papers. Cambridge: Cambridge University Press.

- (1981). Reason, Truth, and History. Cambridge: Cambridge University Press.

Rachels, J. (2000). "Naturalism.” In H. LaFollette (ed.), The Blackwell Guide to Ethical Theory. Malden, MA: Blackwell Publishers, pp. 74-91.

Railton, P. (1993). "What the Non-Cognitivist Helps Us to See the Naturalist Must Help Us to Explain.” In J. Haldane and C. Wright (eds.), Reality, Representation, and Projection. New York: Oxford University Press, pp. 279-300.

Sellars, W. (1980). "A Semantical Solution of the Mind-Body Problem," In J. F. Sicha (ed.), Pure Pragmatics and Possible Worlds: The Early Essays of Wilfrid Sellars. Atascadero, CA: Ridgeview Publishing Company, pp. 219-256.

- (1997). Empiricism and the Philosophy of Mind. Cambridge, MA: Harvard University Press.

Sturgeon, N. L. (1988). "Moral Explanations." In G. Sayre-McCord (ed.), Essays on Moral Realism. Ithaca, NY: Cornell University Press, pp. 229-255.

Wedgwood, R. (1999). "The Price of Non-Reductive Moral Realism." Ethical Theory and Moral Practice 2: 199-215.

Wittgenstein, L. 1958. Philosophical Investigations, G. E. M Anscombe, trans., New York: Macmillan Publishing Company, Inc.

Department of Philosophy

American University of Beirut

Beirut, Lebanon 11072020

koonsj@aub.edu.lb 